\title{
Novel Optical Techniques for Imaging Microcirculation in the Diabetic Foot
}

\author{
O.A. Mennes ${ }^{\mathrm{a}, \mathrm{b}, *}$, J.J. van Netten ${ }^{\mathrm{a}, \mathrm{c}, \mathrm{d}}$, R.H.J.A Slart ${ }^{\mathrm{b}, \mathrm{e}}$, W. Steenbergen ${ }^{\mathrm{b}}$
}

\begin{abstract}
Affiliations
aZiekenhuisgroep Twente, Department of Surgery, Zilvermeeuw 1, Almelo, The Netherlands, 7609 PP

${ }^{b}$ University of Twente, Faculty of Science and Technology, Biomedical Photonic Imaging, Drienerlolaan 5, Enschede, The Netherlands, $7522 \mathrm{NB}$

${ }^{\mathrm{c}}$ Queensland University of Technology, School of Clinical Sciences, Institute of Health and Biomedical Innovation, 2 George St, Brisbane City, Australia, QLD 4000

${ }^{\mathrm{d} A}$ Academisch Medisch Centrum, Universiteit van Amsterdam, Department of Rehabilitation Medicine, Meibergdreef 9, Amsterdam, the Netherlands, 1105 AZ

${ }^{\mathrm{e} U n i v e r s i t y ~ M e d i c a l ~ C e n t e r ~ G r o n i n g e n, ~ M e d i c a l ~ I m a g i n g ~ C e n t e r, ~ D e p a r t m e n t ~ o f ~ N u c l e a r ~ M e d i c i n e ~ a n d ~ M o l e c u l a r ~}$ Imaging, Hanzeplein 1, Groningen, The Netherlands, 9713 GZ
\end{abstract}

\section{*Corresponding author:}

Onno August Mennes,

Ziekenhuisgroep Twente

Department of Surgery

Address: Zilvermeeuw 1; Postbus 7600; 7600 SZ Almelo

Phone +31 88708 3727; Fax +31 53 4891105; E-mail o.mennes@zgt.nl

\begin{abstract}
Background: }}$ The most severe diabetic foot ulcers are those related with critical ischemia, which is primarily diagnosed with non-invasive diagnostics. However, these diagnostics have several disadvantages. For example, they only provide global indications of the (macro)level of ischemia. A potential solution can be found in novel optical imaging techniques for local assessment of the microcirculation in diabetic foot ulcers. This review provides an overview of these imaging techniques (Laser Doppler Perfusion Imaging, Laser Speckle Contrast Imaging; Photoacoustic Imaging and Hyperspectral Imaging) and their applicability for the diagnostic assessment of microcirculation in diabetic foot ulcers. Method: For each technique the following parts are described: a) their technical background; b) general clinical applications; and, c) its application for microcirculation assessment in diabetic foot ulcers. Parts a-b are based on a narrative review of the literature, part $\mathrm{c}$ on a systematic review that was performed in the database Scopus, covering the period from January 1, 2000 to November 31, 2017. Results: Each of these techniques has specific advantages and disadvantages for imaging microcirculation. Potential clinical use depends on measurement aims, and clinical relevance. However, none of the techniques has a strongly established clinical relevance yet: we found a limited number of publications describing clinical outcomes. Future research is needed to determine which technique is the most clinically relevant for the assessment of microcirculation in diabetic foot ulcers. Conclusion: Although promising, the currently available novel optical techniques need to be further improved technically and prospective trials are necessary to evaluate their clinical value.
\end{abstract}

Keywords: Diabetic foot; microcirculation; Laser Doppler Perfusion Imaging; Laser Speckle Contrast Imaging, Photoacoustic Imaging; Hyperspectral Imaging 


\section{Introduction}

Diabetic foot ulcers are a major complication of diabetes mellitus, with high morbidity, mortality, and costs [1-4]. Yearly incidence is estimated to be around 2\%, and life-time incidence lies between 19-34\% [5-7]. It is estimated that $50-75 \%$ of all lower extremity amputations are due to diabetes [8]. Diabetic foot ulcers are the premium cause of hospitalization in patients with diabetes, and are associated with an increase in hospital admission as well as length of stay [2,9]. With a growing number of people with diabetes around the world [10], the burden of complications such as diabetic foot ulcers will continue to grow.

The most severe diabetic foot ulcers are those with critical ischemia: both healing times and length of hospital stay are longest for patients with these ulcers $[1,4]$. The diagnosis of critical ischemia is primarily determined in clinical practice, using non-invasive assessment of blood flow in the feet, by means of assessment of the ankle pressure, toe pressure or transcutaneous oxygen pressure (tcpO2) [6]. As a basis for diagnosis, cut-off values for these assessments to diagnose (critical) ischemia are provided in the international guidelines [6,11]. These values also provide some information regarding the probability of healing of the ulcer without vascular intervention $[6,12]$. However, current non-invasive measurement systems have various disadvantages.

First, these measurements are not necessarily reflecting the situation of ischemia at the site of the ulcer. With different angiosomes providing blood supply to the feet, low blood flow values in one angiosome may not reflect blood supply at the ulcer location, if that ulcer is found at a different supply region [13]. Second, international guidelines indicate that there is a grey area where healing probabilities are unclear [6]. For example, toe pressure values between 30 and $50 \mathrm{mmHg}$ indicate a $20-80 \%$ chance of healing without vascular intervention $[11,12,14]$. This uncertainty may result in delayed vascular intervention and increased healing times. A potential explanation for this uncertainty can be found in arteriovenous shunting, frequently seen in patients with diabetes [15]. In those patients, microcirculation is affected, but this is not reflected in the ankle pressures or toe pressures used for assessment. Overcoming these shortcomings of some of the non-invasive diagnostics is one of the major challenges in the field of diabetic foot ulcers [6].

A potential solution can be found in novel optical imaging techniques for local assessment of the microcirculation. With such techniques, the situation at the location of the ulcer can be assessed, as well as microcirculatory changes to the local perfusion. Ideally, those measurements should be non-invasive, non-contact, non-ionizing, and they should be able to perform local imaging of the complete surface of the foot in a short time procedure [16,17]. This is important in the clinical setting, as diagnostic assessment that does not increase the burden on a patient is favored over advanced imaging techniques such as computed tomography angiography that may pose a significant burden (e.g. radiation dose, iodine-contrast) on a patient, and include longer waiting times as well [6]. Furthermore, when quick and adequate diagnostics can be performed during regular outpatient treatment, they can be used directly in treatment plans.

While various reviews [16-20] have been published in recent years focusing on optical techniques to assess microcirculation, these reviews only focused minimally on microcirculation for diabetic foot ulcers [16-20]. Microcirculatory assessment for diabetic foot ulcers, however, poses unique challenges, different from other vascular disease areas; these include the combination of the presence of an open wound, local microvascular changes (including arteriovenous shunting), potential presence of macrovascular disease, calcifications, infection, edema, and poor collateralization [15].

The aim of this review is to provide an overview of novel optical imaging techniques that could possibly be used as a replacement of or to complement the currently used blood pressure measurements for the diagnostic assessment of microcirculation in diabetic foot ulcers.

In this paper, the following optical techniques will be discussed: (1) Laser speckle based perfusion imaging (1a: Laser Doppler Perfusion Imaging (LDPI), and 1b: Laser Speckle Contrast Imaging (LSCI)), (2) Photoacoustic Imaging (PAI), and (3) Hyperspectral Imaging (HSI). For each technique, we will discuss its technical background, general clinical application, and specific applications (or potential) for the assessment of microcirculation in diabetic foot ulcers. 


\section{Methods}

Based on existing literature [16-20], and our research and clinical experience, four novel optical imaging techniques were selected as topic in this review, as these can be used to measure the microcirculation in tissue: LDPI, LSCI, PAI, and HSI. For each technique a global technical background will be given (part a). Furthermore, one or more general clinical applications of each technique will be described, to present the usefulness in different clinical fields and their possibilities (part b). Finally, to specifically investigate each novel optical technique for imaging microcirculation in diabetic foot ulcers (part c), a systematic review of the literature was performed using the database Scopus (www.scopus.com), covering the period from January 1, 2000, to November 31, 2017. Scopus was chosen because of its multidisciplinary scope. The technological background of the different optical techniques and the clinical relevance in a clinical setting or study led to the need of a database that covered both articles in the medical field and articles outside medicine (e.g. engineering). We did not include publications before 2000 , as both the technological development and the clinical relevance are rapidly changing.

This study's search strategy was based on the six-stage methodological framework of Arksey and O'Malley [21]. One investigator (OAM) searched and selected relevant studies. The main components of the conducted search were (1) microcirculation, (2) diabetic foot ulcer and (3) the optical imaging techniques selected for this review (LDPI, LSCI, HSI, or PAI). Relevant keywords and synonyms were used to combine the three components. The full search strategies are given in Appendix I. Other inclusion criteria were that the articles had to be written in English and published in peer-reviewed journals. In addition to the database search, reference lists of included publications were manually searched for relevant papers based on title and abstract. All relevant studies were included for a full text review by the investigators to determine inclusion or exclusion in this paper. Results from included studies were summarized by one investigator (OAM), and independently checked by another investigator $(\mathrm{JJVN})$.

\section{Laser speckle based perfusion imaging Technical background}

Laser speckle based perfusion imaging techniques (e.g. LDPI and LSCI) use a speckle pattern to measure movement or flow in tissue. When coherent laser light illuminates tissue, the resulting reflection creates a detectable destructive and constructive interference pattern called speckle pattern. Light from different parts of the surface of the tissue reflects in different ways to the detector. The measured intensity of the reflected laser light for each point is based on the addition of all wave amplitudes of the light reaching this point. If the individual waves interfere destructively, the resultant intensity is zero and this will be seen as a dark spot in the speckle pattern. In all other locations of the speckle pattern the waves interfere more or less constructively, leading to a nonzero intensity: these are the bright speckles. Furthermore, the reflecting laser light will be changed by the Doppler effect if the light has interacted with moving structures inside the medium [22,23]. Relative movement between an object that reflects the laser light (e.g. red blood cells) and the detector, generates a change in frequency of the light. For each individual interaction this frequency change, or Doppler shift, depends on the direction and speed of motion. In practice, light can undergo multiple Doppler shifts, also depending on the blood content of the tissue [23,24]. The final result is a dynamic speckle pattern.

LDPI and LSCI both use the dynamic speckle pattern to measure blood flow or microcirculation in tissue. The two techniques, however, differ how they acquire and process data. LDPI uses a fast detector or high-speed camera to capture the dynamic speckle pattern in order to measure all the fluctuations in intensity of the reflected laser light. The average frequency of these fluctuations provides information about the average speed of red blood cells, while the magnitude of intensity fluctuations is used to estimate the blood concentration. The tissue perfusion is then estimated as the product of estimated average speed and estimated blood concentration. The penetration depth of LDPI depends on the laser wavelength. Typically, wavelengths of red light $(633 \mathrm{~nm})$ or near infrared light $(780$ $\mathrm{nm}$ ) are used and a penetration depth of 1-2 mm is achieved. This depth is sufficient and can be used to assess the microcirculation in the capillaries and underlying arterioles and venules and arteriovenous anastomoses deeper in the dermis of the skin (Figure 1) [16,24,25]. However, thickened layers of callus or necrotic tissue can affect the measurement and need to be debrided first, and when debridement cannot take place, measurements may not be reliable at the location of the affected skin. 

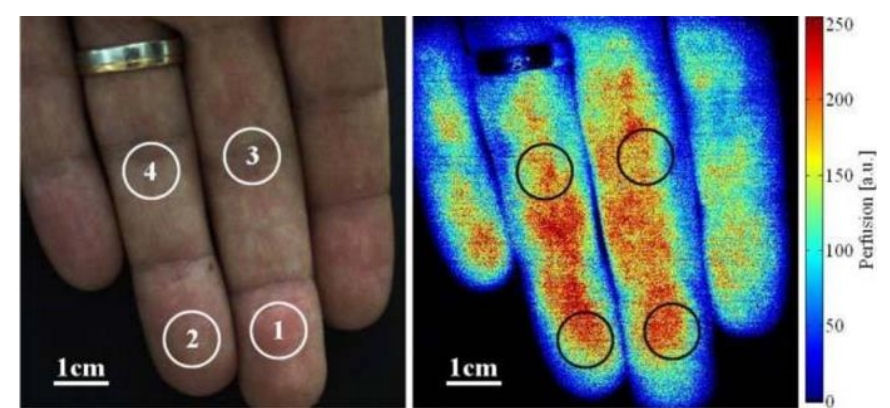

Figure 1: "Color image of fingertips and color-coded blood perfusion map." by Leutenegger et al. [26] licensed under CC BY 3.0

In contrast to LDPI, LSCI uses a camera with a slow response time to capture the dynamic speckle pattern. Consequently, individual speckles will be less clearly visualized, and the contrast of the speckle pattern image is reduced: the contrast in areas with more movement is lower compared to areas with less movement [24,25,27]. Draijer et al. [27] and Briers et al. [25] showed that, based on the quantity of measured contrast in an area, an indication can be obtained of the severity of movement present during the measurement. For medical purposes this is crucial: movement measured in tissue is related to blood flow of the moving red blood cells, and provides opportunities to use LSCI as a tool to measure tissue perfusion (Figure 2) [28]. While LDPI is regarded as giving more quantitative perfusion estimations than LSCI, LDPI for real time imaging is also more expensive since a high-speed camera is needed.
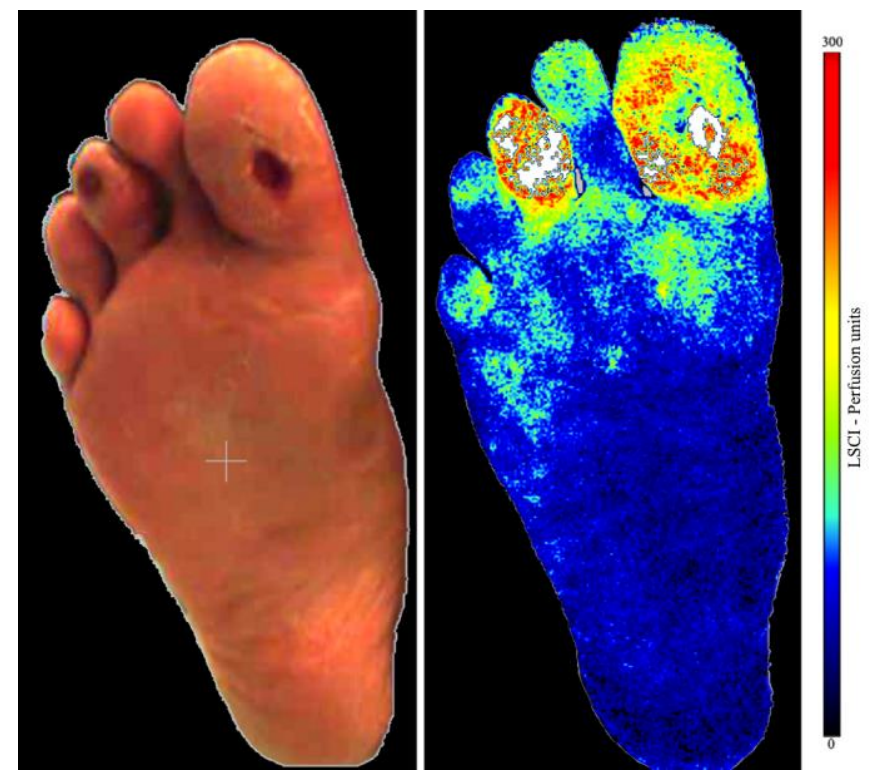

Figure 2: LSCI color image of diabetic foot with ulcer on dig 1 and 3 and color-coded blood perfusion map with increased perfusion values in ulcer area (Pericam PSI). Source: Mennes, O.A., 2016. Color image of diabetic foot and LSCI perfusion map. [photograph] (personal collection).

\section{Clinical application of LDPI}

LDPI has several clinical applications. Primarily it is used for the assessment of burn depth, but it is also applied in other medical fields such as surgery, wound healing, and for general vascular diagnostics [16].

Regarding the assessment of skin burn depth, Hoeksema et al. [29] conducted a study in which they included 40 patients with intermediate depth skin burns to compare and evaluate the LDPI measurements with clinical assessment on days $0,1,3,5$ and 8 . They found an accuracy of skin burn depth assessments using LDPI of $54 \%$ to $100 \%$ while clinical assessment accuracies were lower, namely $41 \%$ to $100 \%$. Furthermore, they found that the LDPI accuracy was significantly higher than clinical accuracy on day $3(\mathrm{p}<0.001)$ and day $5(\mathrm{p}=0.005)$. This indicated that burn depth assessment with LDPI was more reliable than clinical evaluation and, therefore, the authors proposed that all burns of intermediate depth should be analyzed with a combination of both LDPI scanning and clinical evaluation. These findings were confirmed by Pape et al. [30] and Monstrey et al. [31]. They conducted 
a combined large study among 137 patients with skin burns. In total, they measured 433 different burn sides. Based on their measurements, they created a validated coding technique to predict the healing potential (in days) for individual patients. According to the authors, LDPI can be used as a valid tool for the clinical assessment of skin burns.

Anderson et al. [32] used LDPI to quantify blood flow responses to iontophoresis of vasoactive agents; these LDPI findings were then used to examine whether microvascular vasodilation is impaired in patients with systemic sclerosis compared with patients with primary Raynaud's phenomenon and a healthy control group. They concluded that LDPI was feasible to use in measuring blood flow responses to iontophoresis in patients with systemic sclerosis or Raynaud's phenomenon, and that in patients with established systemic sclerosis both endothelium-dependent and endothelium-independent vasodilation are impaired. Furthermore, they recommended using LDPI in order to examine pathophysiology in other groups of patients with rheumatic diseases affecting the microvasculature, and in patients with different severities and durations of scleroderma-spectrum disorders including patients with undifferentiated connective tissue disease. They also indicated that studies to investigate the reproducibility of this technique are still needed [32]. In case reproducibility is demonstrated, LDPI could be used (together with symptom-based measurements) to study disease progression over time and responsiveness to vasoactive treatment. Hughes et al. [33] also used LDPI to measure microcirculation in 16 patients with systemic sclerosis. They examined the blood flow response to topical glyceryl trinitrate compared to placebo in fingertip digital ulcers, looking for differences in pathophysiology between fingertip and extensor lesions.

Another example for the clinical use of LDPI is in the prediction of wound healing after surgical interventions. For instance, Ljung et al. [34] used LDPI to measure microcirculation in the skin around the elbow before and after a total elbow replacement in five rheumatoid arthritis patients to ascertain the possible influence of a compromised blood flow on the wound healing process. Eichhorn et al. [35] also used LDPI scans in wound healing, but then in the field of plastic and reconstructive surgery. They performed measurements and simultaneous two-dimensional imaging of the microcirculation $24,48,72 \mathrm{~h}$ and 5 and 14 days postoperatively in 20 patients, who had had reconstruction procedures performed using random or axial pattern flaps. Eichhorn et al. [35] concluded that the two-dimensional LDPI was a useful technique for follow-up and planning of flaps in plastic and reconstructive surgery. They valued the fact that this technique was a simple and non-invasive method and that it included the possibility of obtaining a representative, real-time image of flap microcirculation for comparison with the surrounding area.

\section{LDPI and the diabetic foot}

The structured search with the combined search terms of "laser Doppler", "diabetic foot" and "(micro)circulation" resulted in 115 hits between 2000 and 2017. Six studies could be included in this review because the majority of the reported studies did not use LDPI, but single point laser Doppler flowmetry, or they were not focused on microcirculation. A description of the six included studies follows.

Although LPDI is not commonly used to measure and assess the levels of ischemia in diabetic foot ulcers, multiple studies are done where LDPI is used to measure the effect of different healing techniques for the diabetic foot ulcer. For example Newton et al. [36] included five patients (seven ulcers) with diabetes type 2 and used LDPI to measure microvascular blood flow before and after two, five, and eight weeks of diabetic foot ulcer treatment with dermal replacement. They found an increase in blood flow of $72 \%$ in the base of five out of the seven ulcers studied. They stated that the found changes in blood flow observed in this study might reflected the different angiogenesis in the granulation tissue or vasodilatation of already existing vessels and that LDPI made it possible to detect and assess those changes. Mirimoto et al. [37] found similar results when they measured the vascularization in dermal substitutes for diabetic foot ulcers. They measured the microcirculation of 11 diabetic foot ulcers with LDPI (Moor LDI2-IR; Moor Instruments Ltd., Axminster, Devon, UK, Figure 3) before and after the placement of a dermal substitute. In this way they were able to measure and compare the different ulcers and assess the microcirculation of the ulcer and its surrounding tissue. Although they did not use the LDPI to predict healing tendency or to diagnose the diabetic foot ulcer, they showed that LDPI was able to measure the circulation in diabetic foot ulcers and that this technique could be used for the assessment of microcirculation [37]. 


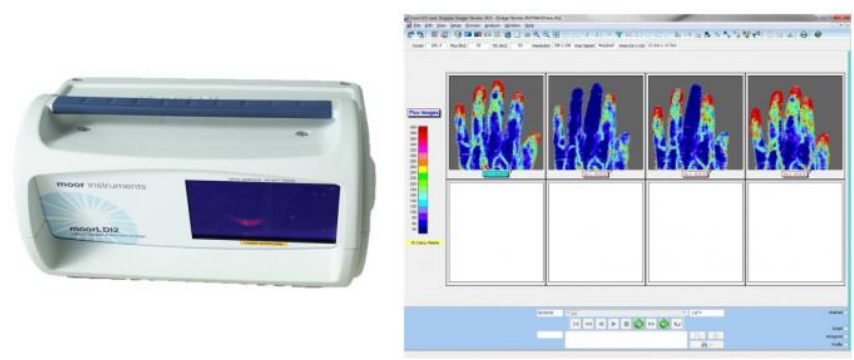

Figure 3: LDPI device (Moor LDI2-IR; Moor Instruments Ltd., Axminster, Devon, UK), as used in the study of Mirimoto et al. [37]. Source https://us.moor.co.uk/

Another study that highlighted the usefulness of LDPI for the diabetic foot population was conducted by Caselli et al. [38]. They used LDPI to measure the vasodilatory response of methyl nicotinate and compared it to the vasodilatory response to acetylcholine and sodium nitroprusside in ten healthy subjects and ten diabetic patients. In this study they used LDPI to measure the vasodilation and microcirculation in the forearm and dorsum of the foot. Although their primary research aim was to measure the vasodilation response of different drugs, the usefulness of LDPI to measure microcirculation in the diabetic foot was shown. For instance, they were able to measure multiple perfusion values of the foot (e.g. base perfusion, peak response to drug, increase in perfusion, area under the curve and time to peak), and found a significant difference between the diabetic population and the healthy control group. This could be an indication that LDPI might be useful for measuring perfusion in a diabetic foot population.

Golster et al. [39] conducted a study to identify whether type 1 diabetes patients (children and adolescents) had signs of microvascular dysfunction and to find a correlation between their microcirculation and different disease parameters (e.g. metabolic control and peripheral nerve dysfunction). They measured the skin blood flow on the dorsum of the foot with LDPI in 37 patients and ten control subjects without diabetes. They performed standard baseline perfusion measurements and applied a stress test to measure post occlusive hyperaemia. They found a correlation between HbA1c (glycated haemoglobin) and blood flow in the foot. Patients with poor metabolic control (acute $\mathrm{HbA} 1 \mathrm{c}>7.5 \%$ ) had an increase in skin blood flow at rest, and when the leg was lowered below heart level, the change in blood flow was significantly reduced. This suggests that low resting blood flow levels contribute to the absence of postural vasoconstrictor response. Golster et al. [39] concluded that LDPI can be used to detect subclinical abnormalities of the microcirculation in young type 1 diabetes.

The final two studies included study population consisting of diverse populations. As their results can be insightful for diabetic foot diagnostics, we did include them in this review. One study was conducted by Gschwandtner et al. [40]. They used LDPI to measure the circulation in ischemic ulcers. Particularly, they investigated the relation between the LDPI signal and a visual inspection with capillary microscopy. Only ten out of the 25 included patients were diabetic foot patients. Gschwandtner et al. [40] found that changes in the circulation measured by LDPI may coincide with changes in the number of visible capillaries within an ischemic ulcer. This can be an indication that LDPI is applicable for the assessment of ischemia in (diabetic) ischemic foot ulcers. The second study, conducted by Petrofsky et al. [41], investigated the effect of electrical stimulation on perfusion in the skin of the hand, leg and foot of patients with wounds (half of the patients had type 2 diabetes). They found an increase in blood flow in the skin after an electrical stimulation. An increase of $53 \%$ was found in the blood flow during the electrical stimulations and this was detectable with LDPI.

\section{Clinical application of LSCI}

LSCI has mainly been applied in clinical pilot studies or pre-clinical studies (such as animal testing) to measure the cutaneous, cerebral and renal blood flow [16]. For example, Mirdell et al. [42] measured perfusion with LSCI in 34 patients with burns at regular intervals after injury until complete reepithelialisation or surgery, and found a significant difference in perfusion between burns that healed early ( $<7$ days) and burns that healed after $>12$ days or for which surgical intervention was needed. Van Vuuren et al. [43] used LSCI for the non-invasive assessment of blood flow of cutaneous wounds. They examined if LSCI could be used as a predictor of venous ulcer healing. A sensitivity of $92.3 \%$, specificity of $75.0 \%$, positive predictive value of $80.0 \%$, and negative predictive value of $75.0 \%$ was found in predicting wound healing based on laser speckle images. The wound edge proved to be the 
best predictor for wound healing. Furthermore, Hecht et al. [44] used non-invasive intraoperative LSCI to predict infarction in 22 patients while they underwent surgery for malignant hemispheric stroke. Bezemer et al. [45] evaluated the use of LSCI for mapping renal cortical microvascular perfusion. They found that LSCI was useful to detect differences in reperfusion dynamics following different durations of ischemia and that renal microvascular perfusion heterogeneities could be assessed by LSCI [45]. In another study, LSCI was used to visualize the microcirculation for real time cerebral blood flow measurement [46] or to measure the optic nerve head blood flow to diagnose for example pre-perimetric glaucoma [47].

Some review papers evaluated the usefulness of LSCI in a clinical setting, for example Humeau-Heurtier [48] and Roustit et al. [49]. Roustit et al. [49] reviewed the advantages and limitations of the main skin provocation tests, combined with measurement techniques such as LSCI. They concluded that LSCI, when coupled with reactivity tests (e.g. post-occlusive reactive hyperemia, local thermal hyperemia, pressure-induced vasodilation, and iontophoresis of vasodilators), offered easy to perform and reliable tools to assess endothelial and neurovascular function in the cutaneous circulation [49]. Humeau-Heurtier et al. [48] described the relevance of LSCI for assessing the vascular function in patients. Besides the usefulness of different evaluation techniques feasible with LSCI (e.g. Postocclusive hyperemia, local thermal hyperemia or microdialysis), they described multiple clinical opportunities (for example; measurements of sleep apnea, exercise training or antiangiogenic therapy) for laser techniques of clinical and treatment efficacy [48].

Finally, Zhang et al. [50] integrated hyperspectral, LSCI, and thermographic imaging modalities in a singleexperimental setup for non-invasive monitoring of tissue oxygenation, perfusion, and thermal emission during the wound healing process. In their experiment, they monitored the healing process of a wound with $3 \mathrm{~mm}$ diameter that was induced on a healthy subject's lower extremity. They were able to identify the different phases of the wound healing process and provided quantitative guidance for different therapeutic options that could be used for diabetic foot ulcers.

\section{LSCI and the diabetic foot}

The structured search with the combined search terms of "laser speckle", "diabetic foot" and "circulation" resulted in a total of 69 documents between 2000 and 2017. Even though some studies were performed to measure circulation in the foot, no studies were found that focused specifically on the measurement of the microcirculation of diabetic foot ulcers with LSCI. This shows that, despite the potential usefulness as discussed in the previous paragraph, LSCI has not yet been studied in people with diabetic foot ulcers. This is an important area for future research.

However, we found two studies closely related to diabetic foot ulcers. Hellmann et al. [51] recruited 12 healthy subjects and 12 persons with type 2 diabetes and used LSCI (PeriCam PSI System, Perimed, Järfälla, Sweden. Figure 4) to determine whether treprostinil iontophoresis increased skin microcirculation. They excluded patients with an active diabetic foot ulcer. They used LSCI to measure the microcirculation in people and showed that it could be used to diagnose small changes in microcirculation in specific areas, such as the skin on the foot or ankle. Based on these results, it can be hypothesized that LSCI may be used similarly in people with diabetic foot ulcers.

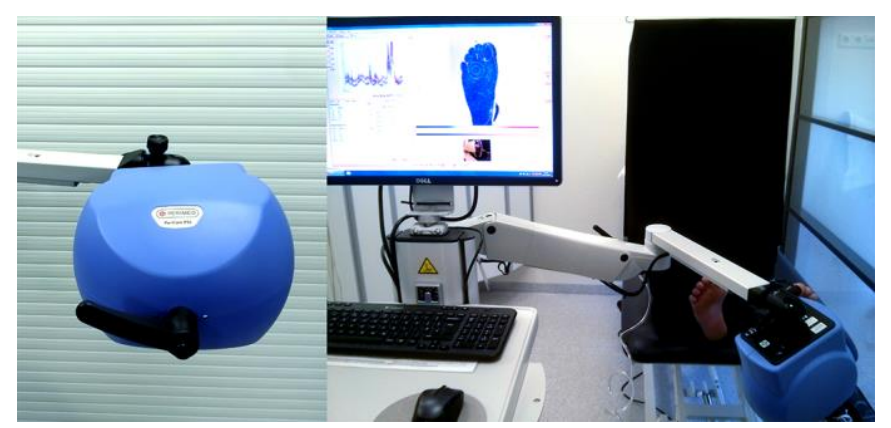

Figure 4: LSCI device (PeriCam PSI System, Perimed, Järfälla, Sweden). Source: Mennes, O.A., 2016. PeriCam PSI System. [photograph] (personal collection). 
Furthermore, a more recent study from Katsui et al. [52] showed the potential usefulness of LSCI in the clinical setting. They used LSCI to assess heating-induced microcirculatory fluctuations in the proximal and distal sites of the dorsal foot of 36 patients with peripheral artery disease (PAD). Of their included PAD patients, 67\% had diabetes mellitus. This means that their results are likely applicable to the diabetic foot population. They found that the LSCI thermal load test discriminated transcutaneous oxygen tension $<30 \mathrm{mmHg}$ with good sensitivity (78.7\%) and specificity (96.2\%). Accordingly, Katsui et al. [52] concluded that LSCI can be used to measure microcirculation of the foot and they expect that it can serve as a useful non-invasive method for diagnosing severe limb ischemia. In conclusion, these two studies showed the potential of LSCI for the assessment of microcirculation in the diabetic foot population, however such a study is not yet performed.

\section{Hyperspectral Imaging Technical background}

Hyperspectral imaging (HSI) is based on optical spectroscopy. HSI uses linearly polarized white light to illuminate the tissue. For the light, three options exist: 1) it can be reflected by the skin, or 2) it penetrates the skin and is absorbed by the tissue, or 3) it is scattered and re-emitted by the tissue [53]. A part of the reflected light or reemitted light will be detected. Based on the polarization of the light, a discrimination can be made between light reflected by the skin (which is still polarized) or light reemitted from the tissue (which has lost its polarization) [53]. By selecting light polarized perpendicular to the polarization of the illuminating light, HSI can select the light that has penetrated into the tissue and exclude reflections from the tissue surface. From the reflected light a spectrum can be acquired and stored in a so-called hypercube. In this way, each pixel in this hypercube represents the local reflectance value at a specific wavelength, reemitted at a specific location on the tissue surface. Based on the measured spectrum and knowledge on light transport in the medium, an absorption spectrum of the tissue can be determined. Because the absorption spectra of many tissue chromophores are known, the characteristics of the tissue can be measured in terms of chromophore content [53-55]. Blood volume and oxygen saturation of blood in dermis can be measured as such. For example, deoxyhemoglobin has a single absorption peak around $554 \mathrm{~nm}$, while oxyhemoglobin has two absorption peaks, around 542 and $578 \mathrm{~nm}$ [56]. Based on these differences, spectroscopic measurements can be performed to visualize microcirculation and local blood oxygen saturation in tissue (Figure 5) [53]. 


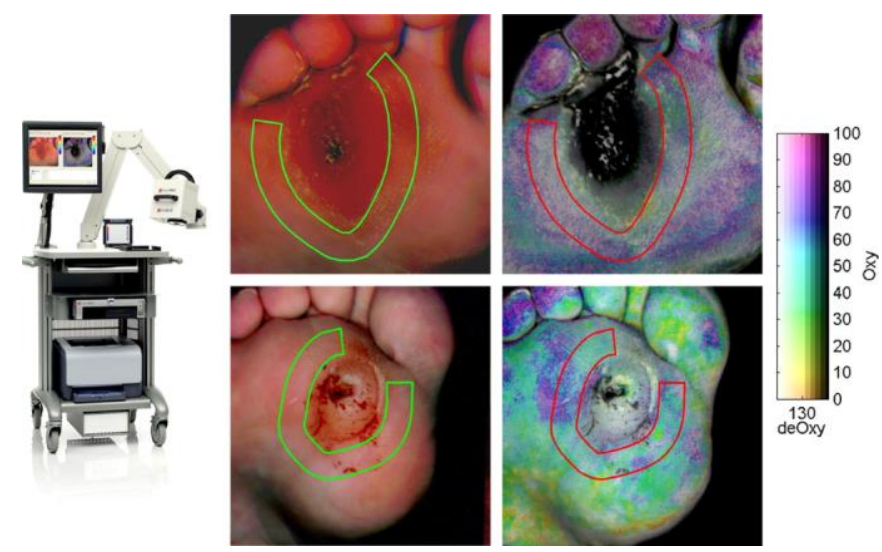

Figure 5: "Visible and HSI of a healing diabetic foot ulcer taken with the HTOM system. The top panels show a healed diabetic foot ulcer case. HTOM values are 75, 34, and 69\% for oxy, deoxy, and StO2, respectively. The bottom panels show a non-healed diabetic foot ulcer case. HTOM values are 60, 53, and 53\% for oxy, deoxy, and StO2, respectively. Tissue oxygenation is higher in the healed ulcer as seen by the more purplish tone compared with the more cyan/green tone. Mean oxy and deoxy values were determined for each ulcer from an approximate 1-cm-thick band drawn within the periwound area." by Nouvong A, et al. [57] licensed under CC BY 3.0

\section{Clinical application of $\mathrm{HSI}$}

HSI bears various possibilities for clinical practice [58]. For example, Ferris et al. [59] used HSI to complement in the diagnosis of cervical neoplasia. They included 111 non-pregnant women and compared the results of an abnormal screening Pap smear (or Pap test: screening procedure for cervical cancer [60]) with an HSI scan of the cervix. They found that both techniques had the same specificity (70\%) but that the sensitivity or HSI was higher (97\%) than for the currently used Pap smear screening (72\%). In this way HSI detected cervical cancer precursors at a greater rate than that of the currently used Pap smear screening [59]. A more recent study by Wang et al. [61] confirmed those results. Wang et al. also investigated the possibilities of HSI for cervical neoplasia diagnosis in a study among 26 patients with cervical abnormalities [61]. They compared the results of HSI with histologic measurements and found that both methods showed great similarities in their diagnostic power [61]. Other examples for the usefulness of HSI in cancer diagnostics are shown in the field of breast cancer [62], prostate cancer [63] and skin cancer [64], regarding the clinical applicability of HSI. However, these studies were conducted among animals (rats or mice) and results may therefore not necessarily translate to clinical practice.

Another example of an animal study that indicated some potential usefulness of HSI in a clinical setting was from Gillies et al. [65]. They used HSI to monitor changes in skin oxygenation during hemorrhagic shock in pigs. They were able to analyze the changes in skin oxygenation during shock and resuscitation in an objective manner with HSI. Cancio et al. [66] performed a similar study. They included seven pig models to measure the effect of a hemorrhagic shock. They found that HSI was a promising non-invasive and non-contact tool for quantifying changes in skin oxygenation during hemorrhagic shock and resuscitation. However, the results of both studies have not yet been confirmed in humans.

HSI has been used to measure oxygen saturation values in the temporal retinal arterioles and venules in healthy volunteers. A study among 14 normal volunteers showed that the mean oxygen saturation of the temporal retinal arterioles was $104.3( \pm 16.7)$, and in the venules $34.8( \pm 17.8)$. This study provided an overview of the normal values of oxygen saturation in the retia and this might help in the diagnosis of retinal vascular occlusion [67]. Additionally, Neville et al. [68] made a database with a normative range of oxyhemoglobin, deoxyhemoglobin, and oxygen saturation of 11 anatomical regions. This database was based on the values of 194 healthy subjects. For each of the 11 regions, a HSI oxygenation map was made. Saturation levels were higher at plantar and palmar regions. During occlusion tests, a decrease in perfusion levels was found and this simulated the effect of ischemia. Neville et al. [68] concluded that HSI was a reliable technique that may help in the diagnosis and treatment of vascular diseases. In line with this study, Chin et al. [69] also investigated if HSI could diagnose the presence or absence of peripheral artery disease (PAD) and if it could predict the severity of the disease. They included 46 healthy (no-PAD) subjects and 65 PAD-patients. Some significant differences in the deoxyhemoglobin values for the plantar metatarsal, arch, and heel angiosomes were found between patients with and without PAD. Furthermore, a significant correlation between the deoxyhemoglobin and the ankle-brachial index (commonly used 
to diagnose PAD) was found. Based on their results they suggested that HSI was able to diagnose the presence of PAD and that it might evaluate the severity of the disease.

\section{HSI and the diabetic foot}

Our structured search with the combined search terms of "hyperspectral", "diabetic foot" and "(micro)circulation" resulted in 86 hits between 2000 and 2017. Six papers were included in our review, as these were the ones in which HSI was specifically applied to the diabetic foot. The majority of the other papers were focused on other contexts (such as wound healing, burn depth assessment or animal studies) or they were not focused on microcirculation. A description of the included papers follows.

Greenman et al. [70] included 108 people (87 diabetes mellitus patients and 21 healthy controls) and used HSI to investigate haemoglobin saturation in the forearm and foot. They indicated that haemoglobin saturation in the foot of people with diabetes was reduced in comparison to the control group. This impairment was further accentuated when there was presence of neuropathy.

In a study by Khaodhiar et al. [71], prediction of diabetic foot ulcer healing was investigated. They included ten persons with type 1 diabetes with 21 foot ulcer sites in total, 13 persons with type 1 diabetes without ulcers, and 14 non-diabetic control subjects. They used medical HSI (CombiVu-R Hyperspectral Technology (HyperMed) to measure the oxyhemoglobin and deoxyhemoglobin at or near the ulcer area and on the upper and lower extremity distant from the ulcer. They found that HSI has the capability to identify microvascular abnormalities and tissue oxygenation in the diabetic foot. Another finding was that both oxyhemoglobin and deoxyhemoglobin were significantly lower (respectively 38 and 26 vs 50 and 49 arbitrary units) in patients with nonhealing ulcers than in healing ulcers. Furthermore, HSI was able to predict foot ulcer healing with a sensitivity of $93 \%$ and a specificity of $86 \%$.

Nouvong et al. [57] performed a prospective single-arm blinded study with 66 patients with diabetes mellitus. The relative concentration of superficial tissue oxyhemoglobin and deoxyhemoglobin was measured with HSI oxygenation mapping (OxyVu; HyperMed, Burlington, MA, Figure 5) from intact tissue bordering the ulcer. A "healing index", derived from oxyhemoglobin and deoxyhemoglobin values, was used to assess the potential for healing. Sensitivity of $80 \%$ and specificity of $74 \%$ was found; those numbers increased to respectively $86 \%$ and $88 \%$ after post-hoc removal of three false-positive and four false-negative cases. However, the exact nature of their "healing index" has never been published, which means the findings cannot be reproduced.

Furthermore, a pilot study ( $\mathrm{n}=2)$ from the same research group [72] showed the results of a combination of HSI and an experimentally validated skin optical model to monitor feet of two patients with diabetes. They aimed to observe temporal changes in local epidermal thickness and oxyhemoglobin concentration, to gain insight into the progression of foot ulcer formation and healing. They observed the ulcers from becoming apparent to the naked eye until they healed and closed. An increase in oxyhemoglobin concentration around the ulcer was found as well as changes is the epidermal thickness. Both effects might be useful for early prediction of diabetic foot ulceration in a clinical setting.

Finally, Jeffcoate et al. [55] explored the use of HSI to predict healing of diabetic foot ulcers in patients with diabetes. They included 43 patients with a diabetic foot ulcer and measured oxygenation with HSI. Their findings suggest that HSI may predict the healing tendency of the ulcer in routine practice. There was a negative association between tissue oxygenation assessed by HSI at baseline and healing by 12 weeks $(p=0.009)$. The mean arbitrary HSI units at the ulcer site was significantly lower $(\mathrm{p}=0.016)$ in the healed ulcer group than in the not healed ulcer group (47.9 vs 61.9 arbitrary units). This is in contrast with the earlier published studies of Khaodhiar et al. [71] and Nouvong et al. [57], who found a positive association between tissue oxygenation and ulcer healing. Jeffcoate et al. explained their negative correlation with the hypothesis that it could be caused by a reduced delivery of oxygen to extravascular tissue or from macrovascular shunting leading to a reduced microvascular transit time that would impair the release of oxygen to the tissues that led to an increase in oxyhaemoglobin at microvascular level. However, evidence for this hypothesis is limited. More research to investigate these interesting contradictory findings is necessary. 


\section{Photoacoustic Imaging \\ Technical background}

Photoacoustic Imaging (PAI), sometimes referred to as optoacoustic imaging, images tissue based on optically induced ultrasound waves. When tissue is illuminated by short laser light pulses (typically 5-100 nanoseconds), the locally absorbed light generates a temperature rise. Since this happens in a short time, a local mechanical stress is generated (the thermo-elastic effect) resulting in the emission of acoustic waves [73,74]. Those acoustic waves can be detected as ultrasound and they can be used with a reconstruction algorithm to visualize the locations where light absorption took place (Figure 6). Because the optical absorption coefficients of different tissue types depend on wavelength of the used laser light, it is possible to target specific types of tissue (e.g. oxy- or deoxyhaemoglobin, melanin or water) with properly chosen wavelengths. For example by measuring the ultrasonic response of light pulses at different wavelengths, the location of blood vessels with high oxyhaemoglobin or deoxyhaemoglobin and a discrimination between arteries and veins can be made [73,74]. Furthermore by using exogenous contrasts, molecular PAI enables visualizing specific cellular functions and molecular processes, to further enhance the imaging signal, especially those materials with strong absorption in the near-infrared (NIR) region where optical attenuation is weaker than the visible light region in vivo. In recent years, great efforts have been devoted to enhance the molecular imaging capability of PAI, and considerable progress has been made in optimizing both the PAI systems for better detection sensitivity, and the contrast agents for better contrast enhancement [75-78]. A limitation of PAI may be that the probe should be in physical contact with the tissue, the measurements cannot be done in a non-contact way.
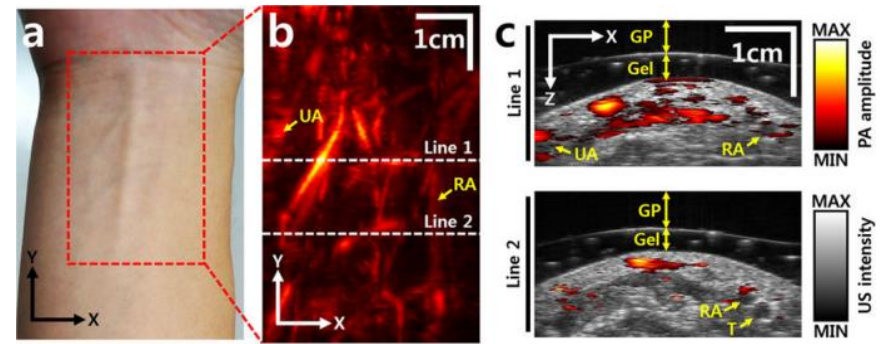

Figure 6: "Photograph (a) and PAI MAP (b) image of a human right forearm. The red dashed rectangle outlines the imaging region. (c) Cross sectional overlaid PAI images at the two white dashed lines in b. GP, gelatin pad; UA, ulnar artery; RA, radial artery; T, tendon; PA, photoacoustic; US, ultrasound; and MAP, maximum amplitude projection.” by Kim J et al.[79] licensed under CC BY 4.0

\section{Clinical application of PAI}

The clinical application of PAI has been investigated in different clinical studies and has been applied as a noninvasive diagnostic technique to assess the microvascularization in different clinical contexts (e.g., breast cancer, skin cancer, port wine stain, synovitis and microvasculature).

Multiple studies have been performed where PAI was used for visualization and diagnosis of breast cancer [8083]. Oraevsky et al. [80] visualized the relative concentration of oxy- and deoxyhemoglobin in the microvasculature in and around malignant breast tumors, using $757 \mathrm{~nm}$ and $1064 \mathrm{~nm}$ laser light. They demonstrated that PAI bears potential for tumor differentiation. However, those results should be interpreted with caution because of methodological shortcomings, such as not mentioning the number of included patients. Manohar et al. [81] used PAI to visualize breast cancer in vivo at a single wavelength (1064 nm). They performed PAI scans in 13 breast cancer patients and presented two cases in their paper. They found that PAI has potential to visualize breast cancer. This potential of PAI in the clinical setting of cancer is further shown in later studies $[82,83]$. The results of a clinical study among 27 skin cancer patients, for example, showed that PAI was able to detect $90 \%$ (18/20) of the malignant lesions [82]. Another study by Heijblom et al. [83] confirmed those findings and demonstrated the potential value of PAI for the imaging of breast tumors. In this study they described the results of 12 new patient measurements for breast cancer analysis and were able to discriminate between breast tumors and cysts. Furthermore, they expected that the potential of PAI could be further improved, when better contrast and imaging depth could be obtained by using better wavelengths or when the image configuration would be changed. 
Another clinical application of PAI is in the field of skin cancer. Zhou et al. [84] performed an animal study with mouse models. They were able to successfully use PAI to detect the tumor depth in vivo till a depth of $3.75 \mathrm{~mm}$ in nude mice. In a later study of Chuah et al. [85] similar results were found when they performed PAI measurements on three patients with skins tumors. They used PAI to acquire a 3D image of the skin tumors and compared those measurements with histological measurements. A good positive correlation between those measurements and the histology was found. Finally, Attia et al. [86] performed a study among 21 skin cancer patients. They were able to discriminate between tumor and healthy skin. Also, they created a 3D image with a spatial resolution of $80 \mu \mathrm{m}$ and found a good correlation $(\mathrm{ICC}=0.81$ ) between this $3 \mathrm{D}$ image and the histological measurements.

PAI has also been used in the context of port wine stain birthmarks. In a study by Viator et al. [87], a self-designed and constructed photoacoustic probe was used to determine their depth in tissue phantoms and in one human subject with a port wine stain on his left upper extremity. They found that the photoacoustic probe determined depth in human skin to $570 \mu \mathrm{m}$ and that the acoustic signals had a high signal-to-noise ratio, indicating that PAI could be feasible to probe human skin deeper than a millimeter, sufficient for most port wine stains.

The feasibility of detection of synovitis in finger joints in rheumatoid arthritis patients with PAI was tested by Van den Berg et al. [88] using a handheld ultrasound probe with integrated diode lasers (Figure 7). They used a portable system to examine inflamed and non-inflamed proximal interphalangeal joints of ten patients and compared these with joints from seven healthy subjects. Next to the PAI scans, they also performed ultrasound power Doppler in order to compare the results. They found that PAI was sensitive to clinically evident synovitis: PAI response was four to tenfold higher in inflamed joints compared with contralateral non-inflamed joints and with joints from healthy subjects ( $\mathrm{p}<0.001$ for both comparisons). Furthermore, they found that ultrasound power Doppler and PAI were strongly correlated (Spearman's $r=0.64$, with $95 \%$ CI: $0.42,0.79$ ), and concluded that PAI is a promising technique for diagnosis and monitoring of inflammation in peripheral joints.

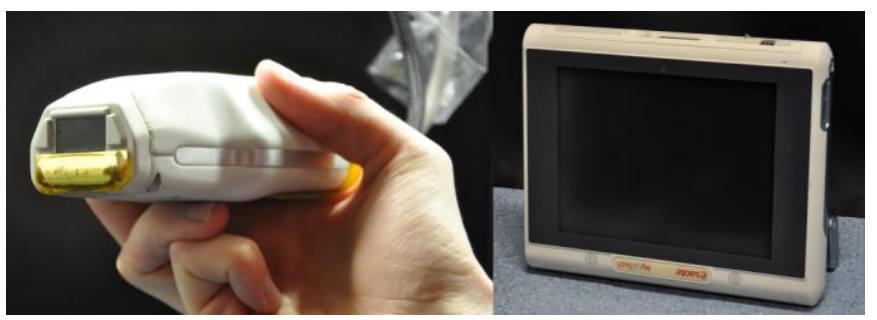

Figure 7: PAI device (handheld PAI probe), as used in the study of Van den Berg et al. [88]. Source: Mennes, O.A., 2018. PAI device. [photograph] (personal collection).

A study by Favazza et al. [89] showed the possibilities of PAI to measure cutaneous microvasculature in human skin. They performed measurements on the palms of healthy volunteers, and were able to inflict and measure the hemodynamic response to occlusion tests to simulate the effect of ischemia in the skin. A decrease in the relative oxygen saturation during those occlusions was found and an increase in saturation during the post occlusive hyperaemia reaction. Another study from Taruttis et al. [90] showed the possibility of measuring the vasculature of the human foot with a handheld PAI probe. In this study they included ten healthy volunteers and measured the arteries and microvascular structures of the feet. They were able to measure the larger arteries (e.g. tibialis posterior and dorsalis pedis) as well as smaller blood vessels with a diameter of less than $100 \mu \mathrm{m}$. Furthermore, based on the measured difference in the oxygenation of blood, they were able to distinguish between arteries and veins and could even monitor the arterial pulse. Taruttis et al. [90] concluded that PAI could be a promising technique for the vascular imaging applications. Although measurements in both studies were performed in healthy volunteers, the results might be an indication for the potential of PAI to measure the levels of ischemia in diabetic foot patients.

\section{PAI and the diabetic foot}

Our full text search with the combined search terms of "photoacoustic" or "optoacoustic" in combination with "diabetic foot" and "vascularization" resulted in zero hits. In the previous paragraph we described the application of PAI in various clinical settings, with some studies suggesting it might be a promising technique to measure vascularization, also in feet. Keeping in mind that the microcirculatory assessment for the diabetic foot population 
differs from other vascular disease areas, as mentioned in the introduction of this paper [15], we conclude that research about the possibilities of PAI in the measurement of microvascularization in the diabetic foot is warranted.

\section{Discussion}

This review provided an overview of novel optical imaging techniques that can be used as a replacement or complementary to the currently used blood pressure measurements for the diagnostic assessment of microcirculation in people with a diabetic foot ulcer (Table 1). We focused on laser speckle based perfusion imaging (LDPI and LSCI), hyperspectral imaging (HSI) and photoacoustic Imaging (PAI). Each of these techniques has specific advantages and disadvantages, and potential use in the clinic depends on the aims of the measurements, as well as the clinical relevance. However, none of the techniques has a clearly established clinical relevance yet, with a only a limited number of publications found describing some clinical diabetic foot ulcerrelated outcomes (Table 2). It needs to be determined in future research which technique is the most clinically relevant for the assessment of the microcirculation in diabetic foot ulcers. With this review, more insight is gained about the pros and cons of the novel optical imaging techniques. These are helpful for clinicians and researchers to decide which technique can be used for their purpose.

Table 1: Overview of characteristics of novel imaging techniques (Laser Doppler Perfusion Imaging (LDPI), Laser Speckle Contrast Imaging (LSCI), Hyperspectral Imaging (HSI) and Photoacoustic Imaging (PAI)

\begin{tabular}{|c|c|c|c|c|c|}
\hline Technique & Physiological measurement & $\begin{array}{l}\text { Penetration depth / } \\
\text { Imaging range }\end{array}$ & Wavelength & Frame rate & $\begin{array}{l}\text { Additional } \\
\text { characteristics }\end{array}$ \\
\hline LDPI & $\begin{array}{l}\text { Movement of blood in micro- } \\
\text { circulation }\end{array}$ & $\begin{array}{l}100 \text { to } 1500 \mathrm{um} \mathrm{/} \\
50 \times 50 \mathrm{~cm}^{2}\end{array}$ & $633-785 \mathrm{~nm}$ & Up to $1 \mathrm{fps}$ & $\begin{array}{l}\text { 2D imaging; compact } \\
\text { device; non-contact } \\
\text { measurement }\end{array}$ \\
\hline LSCI & $\begin{array}{l}\text { Movement of blood in } \\
\text { microcirculation }\end{array}$ & $\begin{array}{l}100 \text { to } 500 \mathrm{um} / \\
24 \times 24 \mathrm{~cm}^{2}\end{array}$ & $785 \mathrm{~nm}$ & Up to $100 \mathrm{fps}$ & $\begin{array}{l}\text { 2D imaging; compact } \\
\text { device; non-contact } \\
\text { measurement }\end{array}$ \\
\hline HSI & $\begin{array}{l}\text { Absorption spectrum of tissue, } \\
\text { mainly haemoglobins }\end{array}$ & $\begin{array}{l}1 \text { to } 5 \mathrm{~mm} / \\
50 \times 50 \mathrm{~cm}^{2}\end{array}$ & $200-2500 \mathrm{~nm}$ & Up to $1000 \mathrm{fps}$ & $\begin{array}{l}\text { 2D imaging; compact } \\
\text { device; non-contact } \\
\text { measurement }\end{array}$ \\
\hline PAI & $\begin{array}{l}\text { Absorption (spectrum) of } \\
\text { tissue, mainly haemoglobins }\end{array}$ & $\begin{array}{l}1 \text { to } 100 \mathrm{~mm} / \\
\text { B-scan of } 4 \mathrm{~cm}\end{array}$ & $808-980 \mathrm{~nm}$ & Up to $50 \mathrm{fps}$ & $\begin{array}{l}\text { 2D/3D imaging; less } \\
\text { compact device; } \\
\text { contact measurement }\end{array}$ \\
\hline
\end{tabular}


Table 2: Overview of relevant diabetic foot studies with novel optical techniques (Laser Doppler Perfusion Imaging (LDPI), Laser Speckle Contrast Imaging (LSCI), Hyperspectral Imaging (HSI) and Photoacoustic Imaging (PAI)

\begin{tabular}{|c|c|c|c|c|c|}
\hline $\begin{array}{l}\text { Study } \\
\text { Year }\end{array}$ & Country & Aim & $\begin{array}{l}\text { Measurement } \\
\text { location }\end{array}$ & $\begin{array}{l}\text { Total Participants } \\
\text { (With diabetes } \\
\text { mellitus) }\end{array}$ & Main findings \\
\hline \multicolumn{6}{|l|}{ LPDI } \\
\hline $\begin{array}{l}\text { Gschwandtner et al. } \\
1999 \text { [40] }\end{array}$ & Austria & $\begin{array}{l}\text { To examine microcirculation within ischemic } \\
\text { ulcers and compare it with capillary density of } \\
\text { adjacent skin. }\end{array}$ & $\begin{array}{l}\text { Ischemic foot } \\
\text { ulcers }\end{array}$ & $25(10)$ & $\begin{array}{l}\text { Changes in the circulation measured by LDPI may coincide with changes in } \\
\text { the number of visible capillaries within an ischemic ulcer. The mean area } \\
\text { flux (in arbitrary units (AUs)) of non-granulation tissue, granulation tissue } \\
\text { and adjacent skin area to the ulcer, were respectively; } 1.30 \pm 1.93 \text { AUs, } \\
2.13 \pm 1.53 \text { AUs and } 1.21 \pm 0.77 \text { AUs. The number of visible capillaries (in } \\
\text { capillaries/mm²) in those areas were respectively } 0.56 \pm 2.06,6.76 \pm 8.39 \text { and } \\
16.80 \pm 7.38 \text {. }\end{array}$ \\
\hline $\begin{array}{l}\text { Newton et al. } \\
2002[36]\end{array}$ & UK & $\begin{array}{l}\text { To investigate if dermal replacement therapy on } \\
\text { diabetic foot ulcers translate into a measurable } \\
\text { increase in blood flow at the base of the ulcers. }\end{array}$ & $\begin{array}{l}\text { Diabetic foot } \\
\text { ulcer }\end{array}$ & $5(5)$ & $\begin{array}{l}\text { An increase in blood flow of } 72 \% \text { perfusion units in the base of five out of } \\
\text { the seven ulcers studied. Mean flux increased from } 324.8 \text { at baseline to } 488,3 \\
\text { PU and } 499.3 \text { PU in week } 2 \text { and } 5 \text {. }\end{array}$ \\
\hline $\begin{array}{l}\text { Caselli et al. } \\
2003[38]\end{array}$ & USA & $\begin{array}{l}\text { To evaluate induced vasodilation in healthy } \\
\text { participants and diabetic neuropathic patients. }\end{array}$ & $\begin{array}{l}\text { Forearm and } \\
\text { dorsum of the } \\
\text { foot }\end{array}$ & $20(10)$ & $\begin{array}{l}\text { Ability to measure multiple perfusion values of the foot and found a } \\
\text { significant difference between the diabetic population and the healthy } \\
\text { control group for the measured difference between peak and baseline blood } \\
\text { flow of the participants }(0.47 \pm 0.3 \mathrm{~V} \text { vs } 1.0 \pm 0.3 \mathrm{~V} ; \mathrm{p}=.001)^{2} \text {. }\end{array}$ \\
\hline $\begin{array}{l}\text { Golster et al. } \\
2005[39]\end{array}$ & Sweden & $\begin{array}{l}\text { To assess the microvascular dysfunction in } \\
\text { children and adolescents with diabetes and its } \\
\text { correlation with various disease parameters. }\end{array}$ & $\begin{array}{l}\text { Dorsum of the } \\
\text { foot }\end{array}$ & $47(37)$ & $\begin{array}{l}\text { A correlation between } \mathrm{HbAlc} \text { and blood flow in the foot: patients with poor } \\
\text { metabolic control }(\mathrm{HbA} 1 \mathrm{c}>7.5 \%) \text { had an increase in skin blood flow at rest } \\
(0.26 \mathrm{~V} \text { versus } 0.17 \mathrm{~V}, \mathrm{P}<0.01)^{2} \text { and when the leg was lowered below heart } \\
\text { level the change in blood flow was significantly reduced }(0.12 \mathrm{~V} \text { versus } 0.23 \\
\left.\mathrm{V}^{2}, \mathrm{P}<0.05\right) \text { compared to patients with HbAlc }<7.5 \% \text { It was concluded that } \\
\text { LDPI can be used to detect subclinical abnormalities of the microcirculation } \\
\text { in young type } 1 \text { diabetes. }\end{array}$ \\
\hline $\begin{array}{l}\text { Petrofsky et al. } \\
2005 \text { [41] }\end{array}$ & USA & $\begin{array}{l}\text { To compare the response of blood flow in normal } \\
\text { skin to that of a variety of wounds after electrical } \\
\text { stimulation. }\end{array}$ & $\begin{array}{l}\text { Hand, leg and } \\
\text { foot }\end{array}$ & $10(5)$ & $\begin{array}{l}\text { An increase in blood flow in the skin after an electrical stimulation. An } \\
\text { increase of } 52.1 \% \text { (from } 192 \pm 74.2 \text { to } 292.0 \pm 81.4 \text { blood flux units) was } \\
\text { found in the blood flow during the electrical stimulations and this was } \\
\text { detectable with LDPI. }\end{array}$ \\
\hline $\begin{array}{l}\text { Mirimoto et al. } \\
2014 \text { [37] }\end{array}$ & Japan & $\begin{array}{l}\text { To compare neovascularization in different } \\
\text { dermal substitutes for diabetic foot ulcers. }\end{array}$ & $\begin{array}{l}\text { Diabetic foot } \\
\text { ulcer }\end{array}$ & $11(11)$ & $\begin{array}{l}\text { Ability to measure and compare the different ulcers and assess the } \\
\text { microcirculation of the ulcer and its surrounding tissue. LDPI was able to } \\
\text { measure a significant }(\mathrm{p}<0.01) \text { increase in perfusion units after } 3 \text { weeks in } \\
\text { comparison to baseline values. LDPI could be used for the assessment of } \\
\text { microcirculation. }\end{array}$ \\
\hline \multicolumn{6}{|r|}{ e } \\
\hline $\begin{array}{l}\text { Hellmann et al. } \\
2015 \text { [51] }\end{array}$ & France & $\begin{array}{l}\text { To determine whether treprostinil iontophoresis } \\
\text { increases skin microcirculation in the malleolus } \\
\text { area of healthy subjects and diabetic patients. }\end{array}$ & $\begin{array}{l}\text { Foot ulcer, } \\
\text { foot and ankle }\end{array}$ & $24(12)$ & $\begin{array}{l}\text { LSCI could be used to diagnose small changes in microcirculation in } \\
\text { specific areas, such as the skin on the foot or ankle. }\end{array}$ \\
\hline $\begin{array}{l}\text { Katsui et al. } \\
2017[52]\end{array}$ & Japan & $\begin{array}{l}\text { To establish an LSCI-based protocol for assessing } \\
\text { the severity of limb ischemia. }\end{array}$ & $\begin{array}{l}\text { Dorsum of the } \\
\text { foot }\end{array}$ & $36(24)$ & $\begin{array}{l}\text { LSCI thermal load test discriminated transcutaneous oxygen tension }<30 \\
\mathrm{mmH} \text { m with good sensitivity }(78.7 \%) \text { and specificity }(96.2 \%) \text {. Accordingly, } \\
\text { it was concluded that LSCI can be used to measure microcirculation of the } \\
\text { foot and they expect that it can serve as a useful non-invasive method for } \\
\text { diagnosing severe limb ischemia. }\end{array}$ \\
\hline $\begin{array}{l}\text { HSI } \\
\text { Greenman et al. } \\
2005[70]\end{array}$ & USA & $\begin{array}{l}\text { To use HSI to measure oxygen delivery and } \\
\text { oxygen extraction of skin tissue based on the }\end{array}$ & $\begin{array}{l}\text { Forearm and } \\
\text { foot }\end{array}$ & $108(87)$ & $\begin{array}{l}\text { Oxyhaemoglobin saturation in the foot of people with diabetes was reduced } \\
\text { in comparison to the control group }(20 \pm 5 \text { vs } 29 \pm 7 ; \mathrm{p}<0.0001) \text {. This }\end{array}$ \\
\hline
\end{tabular}


measurement of oxyhaemoglobin and deoxyhaemoglobin in blood.

Khaodhiar et al.

To assess tissue oxygenation around diabetic foot

ulcers and assess the ability of this technique to

predict the healing and track the progress of foot

ulcers.

Nouvong et al.

2009 [57]

USA

To test the accuracy of HSI in evaluating the healing potential of diabetic foot ulcers.

Diabetic foot $66(66)$

To demonstrate the capability of reflectance spectroscopy to rapidly, non-invasively, an simultaneously determination of epiderma melanin concentration and thickness, dermal blood volume and oxygen saturation.

2011 [72]

Jeffcoate et al.

To explore the uxygen saturation.

(HSI) tore the use of hyperspectral imaging

2015 [55]

patients with diabetes.

impairment was further accentuated with the presence of neuropathy $(19 \pm 7$ vs $29 \pm 7 \mathrm{p}<0.0001$ )

HSI has the capability to identify microvascular abnormalities and tissue oxygenation in the diabetic foot. Furthermore, both oxyhemoglobin (oxy) and deoxyhemoglobin (deoxy), measured in arbitrary HSI units (AUs), were significantly lower $(\mathrm{p}<0.0001)$ in patients with nonhealing ulcers (oxy $38 \pm 2$ AUs; deoxy $26 \pm 3$ AUs) than in healing ulcers (oxy $50 \pm 3$ AUs; deoxy $49 \pm 2$ AUs).

Sensitivity of $80 \%$ and a specificity of $74 \%$ was found to predict healing within 24 weeks; those numbers increased to respectively $86 \%$ and $88 \%$ fter post-hoc removal of three false-positive and four false-negative cases. An increase in epidermal thickness that was associated with a decrease in oxyhemoglobin concentration prior to ulceration was found. Both effects might be useful for early prediction of diabetic foot ulceration in a clinical

A negative association between tissue oxygenation as assessed by HSI a baseline and healing by 12 weeks: The median arbitrary HSI units (AUs) a the ulcer site were significantly lower $(\mathrm{p}=0.016)$ in the healed ulcer group (47.9 AUs [95\% CI; 12.3-75.5AUs]) than in the not healed ulcer group (61.9 AUs [95\% CI; 27.2-80.4 AUs]).

na

Note: ${ }^{1}$ Participants are the total number of participants in the study. The number of participants with diabetes mellitus is shown in brackets. ${ }^{2}$ No studies found. 
The first important consideration is the technical background of each technique. This determines the aspect of microcirculation that can be captured. If blood flow or blood circulation should be measured, both LDPI and LSCI would be the techniques of choice, as they measure the motion of blood from dynamic speckle patterns [24]. For the measurement of the composition of tissue or the (relative) concentration of oxy-and deoxyhaemoglobin in blood, HSI or (multiwavelength) PAI should be used. For the measurement of the presence of blood (different from blood flow or blood pressure), both HSI or PAI would be a good choice, as both techniques measure the presence of blood based on its absorption of light, which does not depend on movement in tissue. For 2D imaging in the plane of the skin surface, HSI would be well suited, for 3D imaging PAI is necessary. In comparison with LSCI, LDPI and HSI, PAI is able to deliver 3D images instead of 2D ones. This could be particularly useful in cases when a better overview is necessary, for example before or during revascularization of the foot.

Second, aspects such as costs, usability, and the need for non-contact methods should be considered. Generally, the costs for the equipment for each technique are tens of thousands of euros. Most PAI systems are quite expensive because of the laser, however, these costs can be reduced when a diode laser is used, as was for example applied in the study by van den Berg et al. [88]. Furthermore, LDPI systems are more expensive than LSCI because the camera for LDPI needs to have a higher frame-rate to capture the LDPI data.

User friendliness differs among the four optical imaging techniques. PAI systems are usually less compact and therefore less convenient to use in the clinical setting. This might be fixed with the current development of handheld PAI probes, as described in multiple studies $[74,84,86,88,90]$, although the scanning surface and therefore the imaging dimensions are smaller in those devices. LDPI, LSCI and HSI are all available in compact systems and usable on portable trolleys for bedside measurements for the patient.

In the clinical setting of diabetic foot ulcers, it is preferable to use non-contact methods [16,17]. Regarding this aspect, PAI is less applicable than the other three systems because PAI needs to have skin-contact in order to detect the returning ultrasound. This is performed using contact gel or water; however, and is not suitable in the context of an open wound, and therefore less desirable in the measurement of diabetic foot ulcers.

We discussed four techniques in this review paper, however, other promising imaging techniques are available that may also be relevant in the diabetic foot ulcers. One example is Infrared thermography, which is currently used in the diagnostics of inflammation and in the prevention of diabetic foot ulcers [91,92]. However, it is not yet commonly used for the assessment of microcirculation and therefore it was not included in this review.

\section{Future research}

As outlined above, additional research on LSCI, LDPI, HSI, and PAI for the assessment of microcirculation in the diabetic foot is needed, in both the technical as well in the clinical setting. Some examples of a future research agenda are as follows.

LSCI has great potential as a real-time non-invasive technique. However, the used perfusion units (PU's) are not yet correlated to non-arbitrary units. For example, it is not possible to measure PU in flow units such as ml blood $/ \mathrm{min} / \mathrm{mm}^{3}$ tissue. Furthermore, the clinical relevance of LSCI is unknown. This is also the case for LDPI measurements. Although LDPI is more well-known since it is possible to translate the measured Doppler shift to velocity, the correlation to healing tendency is not known and therefore and improvement can be achieved in this area.

Both HSI and PAI have major potential when measuring the composition of tissue or concentration of blood, and its oxygen saturation. However, the pathologic consequences based on the different concentration levels of blood are not well known. For example Jeffcoate et al. [53] found a negative association between tissue oxygenation and healing, what is in contrast with studies of Khaodhiar et al. [68] and Nouvong et al. [69], who found a positive association between tissue oxygenation and ulcer healing. More research to the healing tendency of ulcers based on the measured concentrations of oxy- and deoxyhaemoglobin could give more insight in the healing process of wounds and the prediction of ulcer healing. 
For PAI there are zero publications where PAI is used to measure the microcirculation for the diabetic foot. Only a few small clinical studies are available that are applicable for the diabetic foot population. It is therefore interesting to look further into the usefulness of PAI in this field. One advantage of PAI is that it can conduct 3Dimaging. It would be of interest to examine the possibilities of this feature for the diabetic foot, because of better delineation of the affected bone and soft tissue involvement, beside the vascular blood compartment evaluation.

\section{Conclusion}

In this review, four novel optical techniques for assessment of microcirculation in people with a diabetic foot ulcer were evaluated. All of them seem promising for the measurement of various aspects of the microcirculation in and around a diabetic foot ulcer. However, none of the techniques has been sufficiently tested in a clinical setting with people with diabetic foot ulcers, and as such their added value for the clinic is currently still uncertain. Although the possibilities are promising, the current novel optical imaging techniques need to be technically improved and prospective trials are necessary to evaluate their clinical value.

\section{Acknowledgements}

This study was supported by the 'Pioneers in Health Care' Innovation Fund of the University of Twente. 


\section{References}

[1] Alexiadou K, Doupis J. Management of diabetic foot ulcers. Diabetes Ther. 2012;3:1-15.

[2] Kerr M, Rayman G, Jeffcoate WJ. Cost of diabetic foot disease to the National Health Service in England. Diabet Med. 2014 Dec;31:1498-504.

[3] Prompers L, Huijberts M, Schaper N, Apelqvist J, Bakker K, Edmonds M, et al. Resource utilisation and costs associated with the treatment of diabetic foot ulcers. Prospective data from the Eurodiale Study. Diabetologia. 2008;51:1826-34.

[4] Prompers L, Schaper N, Apelqvist J, Edmonds M, Jude E, Mauricio D, et al. Prediction of outcome in individuals with diabetic foot ulcers: Focus on the differences between individuals with and without peripheral arterial disease. The EURODIALE Study. Diabetologia. 2008;51:747-55.

[5] Bakker K, Apelqvist J, Lipsky BA, Van Netten JJ, Schaper NC. The 2015 IWGDF guidance documents on prevention and management of foot problems in diabetes: development of an evidence-based global consensus. Diabetes Metab Res Rev. 2015 Sep 27;

[6] Hinchliffe R, Brownrigg J, Apelqvist J, Boyko EJ, Fitridge R, Mills J, et al. IWGDF guidance on the diagnosis, prognosis and management of peripheral artery disease in patients with foot ulcers in diabetes. Diabetes Metab Res Rev. 2016;32 Suppl 1:37-44.

[7] Armstrong DG, Boulton AJM, Bus SA. Diabetic Foot Ulcers and Their Recurrence. N Engl J Med. 2017;376:2367-75.

[8] Narres M, Kvitkina T, Claessen H, Droste S, Schuster B, Morbach S, et al. Incidence of lower extremity amputations in the diabetic compared with the non-diabetic population: A systematic review. Vol. 12, PLoS ONE. 2017.

[9] Skrepnek GH, Mills JL, Lavery LA, Armstrong DG. Health care service and outcomes among an estimated 6.7 million ambulatory care diabetic foot cases in the U.S. Diabetes Care. 2017 Jul;40:936-42.

[10] Aldworth J, Bache N Al, Hegelund MH, Hirst SM, Linnenkamp U, Magliano D, et al. IDF Diabetes Atlas 7th edition. 2015. 144 p.

[11] Brownrigg JRW, Hinchliffe RJ, Apelqvist J, Boyko EJ, Fitridge R, Mills JL, et al. Effectiveness of bedside investigations to diagnose peripheral artery disease among people with diabetes mellitus: a systematic review. Diabetes Metab Res Rev. 2016 Jan;32:119-27.

[12] Brownrigg JRW, Hinchliffe RJ, Apelqvist J, Boyko EJ, Fitridge R, Mills JL, et al. Performance of prognostic markers in the prediction of wound healing or amputation among patients with foot ulcers in diabetes: A systematic review. Diabetes Metab Res Rev. 2016 Jan;32:128-35.

[13] Sumpio BE, Forsythe RO, Ziegler KR, Van Baal JG, Lepantalo MJA, Hinchliffe RJ. Clinical implications of the angiosome model in peripheral vascular disease. J Vasc Surg. 2013;58:814-26.

[14] Elgzyri T, Larsson J, Thörne J, Eriksson KF, Apelqvist J. Outcome of ischemic foot ulcer in diabetic patients who had no invasive vascular intervention. Eur J Vasc Endovasc Surg. 2013;46:110-7.

[15] Boulton AJM, Scarpello JHB, Ward JD. Venous oxygenation in the diabetic neuropathic foot: Evidence of arteriovenous shunting? Diabetologia. 1982 Jan;22:6-8.

[16] Allen J, Howell K. Microvascular imaging: Techniques and opportunities for clinical physiological measurements. Physiol Meas. 2014;35.

[17] Forsythe RO, Hinchliffe RJ. Assessment of foot perfusion in patients with a diabetic foot ulcer. Diabetes Metab Res Rev. 2016;32:232-8.

[18] Leahy MJ, Enfield JG, Clancy NT, O’Doherty J, McNamara P, Nilsson GE. Biophotonic methods in microcirculation imaging. Med Laser Appl. 2007;22:105-26.

[19] Sakr Y. Techniques to assess tissue oxygenation in the clinical setting. Transfus Apher Sci. 2010;43:7994.

[20] Sowa MG, Kuo W-C, Ko AC-T, Armstrong DG. Review of near-infrared methods for wound assessment. J Biomed Opt. 2016;21:91304.

[21] Arksey H, O’Malley L. Scoping studies: Towards a methodological framework. Int J Soc Res Methodol Theory Pract. 2005 Feb;8:19-32.

[22] Nilsson GE, Tenland T, Oberg PA. Evaluation of a Laser Doppler Flowmeter for Measurement of Tissue Blood Flow. IEEE Trans Biomed Eng. 1980 Oct;BME-27:597-604.

[23] Stern MD. In vivo evaluation of microcirculation by coherent light scattering. Nature. 1975 Mar 6;254:56-8.

[24] Briers D. Laser Doppler, speckle and related techniques for blood perfusion mapping and imagingLaser Doppler, speckle and related techniques for blood perfusion mapping and imaging. 2001;35.

[25] Briers JD. Laser speckle contrast imaging for measuring blood flow. 2007;XXXVII:14.

[26] Leutenegger M, Martin-Williams E, Harbi P, Thacher T, Raffoul W, André M, et al. Real-time full field laser Doppler imaging. Biomed Opt Express. 2011 Jun 1;2:1470-7.

[27] Draijer M, Hondebrink E, Van Leeuwen T, Steenbergen W. Review of laser speckle contrast techniques for visualizing tissue perfusion. Lasers Med Sci. 2009;24:639-51. 
[28] Bezemer R, Klijn E, Khalilzada M, Lima A, Heger M, van Bommel J, et al. Validation of near-infrared laser speckle imaging for assessing microvascular (re)perfusion. Microvasc Res. 2010;79:139-43.

[29] Hoeksema H, Van de Sijpe K, Tondu T, Hamdi M, Van Landuyt K, Blondeel P, et al. Accuracy of early burn depth assessment by laser Doppler imaging on different days post burn. Burns. 2009;35:36-45.

[30] Pape SA, Baker RD, Wilson D, Hoeksema H, Jeng JC, Spence RJ, et al. Burn wound healing time assessed by laser Doppler imaging (LDI). Part 1: Derivation of a dedicated colour code for image interpretation. Burns. 2012;38:187-94.

[31] Pape SA, Baker RD, Wilson D, Hoeksema H, Jeng JC, Spence RJ, et al. Burn wound healing time assessed by laser Doppler imaging (LDI). Part 1: Derivation of a dedicated colour code for image interpretation. Burns. 2012;38:187-94.

[32] Anderson ME, Moore TL, Lunt M, Herrick AL. Digital iontophoresis of vasoactive subtances as measured by laser Doppler imaging - A non-invasive technique by which to measure microvascular dysfunction in Raynaud's phenomenon. Rheumatology. 2004 Aug 1;43:986-91.

[33] Hughes M, Moore T, Manning J, Wilkinson J, Dinsdale G, Roberts C, et al. Reduced perfusion in systemic sclerosis digital ulcers (both fingertip and extensor) can be increased by topical application of glyceryl trinitrate. Microvasc Res. 2017;111:32-6.

[34] Ljung P, Bornmyr S, Svensson H. Wound healing after total elbow replacement in rheumatoid arthritis wound complications in 50 cases and laser-doppler imaging of skin microcirculation. Acta Orthop. 1995 Jan 8;66:59-63.

[35] Eichhorn W, Auer T, Voy ED, Hoffmann K. Laser Doppler imaging of axial and random pattern flaps in the maxillo-facial area. A preliminary report. J Cranio-Maxillofacial Surg. 1994 Oct;22:301-6.

[36] Newton DJ, Khan F, Belch JJF, Mitchell MR, Leese GP. Blood flow changes in diabetic foot ulcers treated with dermal replacement therapy. J Foot Ankle Surg. 2002 Jul;41:233-7.

[37] Morimoto N, Kakudo N, Valentin Notodihardjo P, Suzuki S, Kusumoto K. Comparison of neovascularization in dermal substitutes seeded with autologous fibroblasts or impregnated with bFGF applied to diabetic foot ulcers using laser Doppler imaging. J Artif Organs. 2014 Dec 16;17:352-7.

[38] Caselli A, Hanane T, Jane B, Carter S, Khaodhiar L, Veves A. Topical methyl nicotinate-induced skin vasodilation in diabetic neuropathy. J Diabetes Complications. 2003;17:205-10.

[39] Golster H, Hyllienmark L, Ledin T, Ludvigsson J, Sjoberg F. Impaired microvascular function related to poor metabolic control in young patients with diabetes. ClinPhysiol FunctImaging. 2005;25:100-5.

[40] Gschwandtner ME, Ambrózy E, Schneider B, Fasching S, Willfort A, Ehringer H. Laser doppler imaging and capillary microscopy in ischemic ulcers. Atherosclerosis. 1999 Jan 3;142:225-32.

[41] Petrofsky J, Schwab E, Lo T, Cúneo M, George J, Kim J, et al. Effects of electrical stimulation on skin blood flow in controls and in and around stage III and IV wounds in hairy and non hairy skin. Med Sci Monit. 2005;11:CR309-16.

[42] Mirdell R, Iredahl F, Sjöberg F, Farnebo S, Tesselaar E. Microvascular blood flow in scalds in children and its relation to duration of wound healing: A study using laser speckle contrast imaging. Burns. 2016;42:648-54.

[43] van Vuuren TMAJ, Van Zandvoort C, Doganci S, Zwiers I, tenCate-Hoek AJ, Kurstjens RLM, et al. Prediction of venous wound healing with laser speckle imaging. Phlebology. 2017;32:658-64.

[44] Hecht N, Müller M-M, Sandow N, Pinczolits A, Vajkoczy P, Woitzik J. Infarct prediction by intraoperative laser speckle imaging in patients with malignant hemispheric stroke. J Cereb Blood Flow Metab. 2016;36:1022-32.

[45] Bezemer R, Legrand M, Klijn E, Heger M, Post ICJH, van Gulik TM, et al. Real-time assessment of renal cortical microvascular perfusion heterogeneities using near-infrared laser speckle imaging. Opt Express. 2010;18:15054-61.

[46] Dunn AK. Laser speckle contrast imaging of cerebral blood flow. Ann Biomed Eng. 2012;40:367-77.

[47] Shiga Y, Kunikata H, Aizawa N, Kiyota N, Maiya Y, Yokoyama Y, et al. Optic Nerve Head Blood Flow, as Measured by Laser Speckle Flowgraphy, Is Significantly Reduced in Preperimetric Glaucoma. Curr Eye Res. 2016;41:1447-53.

[48] Humeau-Heurtier A, Guerreschi E, Abraham P, Mahe G. Relevance of laser doppler and laser speckle techniques for assessing vascular function: State of the art and future trends. IEEE Trans Biomed Eng. 2013;60:659-66.

[49] Roustit M, Cracowski JL. Assessment of endothelial and neurovascular function in human skin microcirculation. Trends Pharmacol Sci. 2013;34:373-84.

[50] Zhang S, Gnyawali S, Huang J, Ren W, Gordillo G, Sen CK, et al. Multimodal imaging of cutaneous wound tissue. J Biomed Opt. 2015;20:16016.

[51] Hellmann M, Roustit M, Gaillard-Bigot F, Cracowski JL. Cutaneous iontophoresis of treprostinil, a prostacyclin analog, increases microvascular blood flux in diabetic malleolus area. Eur J Pharmacol. 2015;758:123-8. 
[52] Katsui S, Inoue Y, Igari K, Toyofuku T, Kudo T, Uetake H. Novel assessment tool based on laser speckle contrast imaging to diagnose severe ischemia in the lower limb for patients with peripheral arterial disease. Lasers Surg Med. 2017;49:645-51.

[53] Yudovsky D, Nouvong A, Pilon L. Hyperspectral imaging in diabetic foot wound care. J Diabetes Sci Technol. 2010 Sep;4:1099-113.

[54] Gould LJ. Technology: Noninvasive Assessment of Lower Extremity Healing Potential. Foot Ankle Spec. 2008 Apr;1:115-6.

[55] Jeffcoate WJ, Clark DJ, Savic N, Rodmell PI, Hinchliffe RJ, Musgrove A, et al. Use of HSI to measure oxygen saturation in the lower limb and its correlation with healing of foot ulcers in diabetes. Diabet Med. 2015;32:798-802.

[56] Tuchin VV. Tissue optics: light scattering methods and instruments for medical diagnosis. SPIE Pres. 2007. 3-142 p.

[57] Nouvong A, Hoogwerf B, Mohler E, Davis B, Tajaddini A, Medenilla E. Evaluation of diabetic foot ulcer healing with hyperspectral imaging of oxyhemoglobin and deoxyhemoglobin. Diabetes Care. 2009 Nov 1;32:2056-61.

[58] Lu G, Fei B. Medical hyperspectral imaging: a review. J Biomed Opt. 2014 Jan 20;19:10901.

[59] Ferris DG, Lawhead R a, Dickman ED, Holtzapple N, Miller J a, Grogan S, et al. Multimodal hyperspectral imaging for the noninvasive diagnosis of cervical neoplasia. J Low Genit Tract Dis. 2001;5:65-72.

[60] Pap Smear-ClinicalKey [Internet]. https://www.clinicalkey.com/\#!/content/medical_procedure/19-s2.0mp_FM-020. [cited 2018 Jan 9]. Available from:

https://www.clinicalkey.com/\#!/content/medical_procedure/19-s2.0-mp_FM-020

[61] Wang C, Zheng W, Bu Y, Chang S, Zhang S, Xu RX. Multi-scale hyperspectral imaging of cervical neoplasia. Arch Gynecol Obstet. 2015;293:1309-17.

[62] Panasyuk S V., Yang S, Faller D V., Ngo D, Lew RA, Freeman JE, et al. Medical hyperspectral imaging to facilitate residual tumor identification during surgery. Cancer Biol Ther. 2007;6:439-46.

[63] Akbari H, Halig L V., Schuster DM, Osunkoya A, Master V, Nieh PT, et al. Hyperspectral imaging and quantitative analysis for prostate cancer detection. J Biomed Opt. 2012;17:760051.

[64] Kong SG, Martin M, Vo-Dinh T. Hyperspectral Fluorescence Imaging for Mouse Skin Tumor Detection. ETRI J. 2006 Dec 7;28:770-6.

[65] Gillies R, Freeman JE, Cancio LC, Brand D, Hopmeier M, Mansfield JR. Systemic Effects of Shock and Resuscitation Monitored by Visible Hyperspectral Imaging. Diabetes Technol Ther. 2003 Oct;5:847-55.

[66] Cancio LC, Batchinsky AI, Mansfield JR, Panasyuk S, Hetz K, Martini D, et al. Hyperspectral Imaging: A New Approach to the Diagnosis of Hemorrhagic Shock. J Trauma Inj Infect Crit Care. 2006 May;60:1087-95.

[67] Mordant DJ, Al-Abboud I, Muyo G, Gorman A, Sallam A, Ritchie P, et al. Spectral imaging of the retina. Eye. 2011 Mar 10;25:309-20.

[68] Neville R, Gupta S. Establishment of normative perfusion values using hyperspectral tissue oxygenation mapping technology. 2009 Nov;6:156-61.

[69] Chin JA, Wang EC, Kibbe MR. Evaluation of hyperspectral technology for assessing the presence and severity of peripheral artery disease. J Vasc Surg. 2011 Dec;54:1679-88.

[70] Greenman RL, Panasyuk S, Wang X, Lyons TE, Dinh T, Longoria L, et al. Early changes in the skin microcirculation and muscle metabolism of the diabetic foot. Lancet. 2005;366:1711-7.

[71] Khaodhiar L, Dinh T, Schomacker K, Panasyuk S V., Freeman JE, Lew R, et al. The Use of Medical Hyperspectral Imaging (MHSI) To Evaluate Microcirculatory Changes in Diabetic Foot Ulcers and Predict Clinical Outcomes. Diabetes Care. 2007;30:903-10.

[72] Yudovsky D, Nouvong A, Schomacker K, Pilon L. Monitoring temporal development and healing of diabetic foot ulceration using hyperspectral imaging. J Biophotonics. 2011;4:565-76.

[73] Xia J, Yao J, Wang L V. Photoacoustic tomography: principles and advances. Electromagn waves (Cambridge, Mass). Jan;147:1-22.

[74] Gujrati V, Mishra A, Ntziachristos V. Molecular imaging probes for multi-spectral optoacoustic tomography. Chem Commun. 2017;53:4653-72.

[75] Lee HY, Hyun SH, Lee KS, Kim B-T, Kim J, Shim YM, et al. Volume-based parameter of 18)F-FDG $\mathrm{PET} / \mathrm{CT}$ in malignant pleural mesothelioma: prediction of therapeutic response and prognostic implications. Ann Surg Oncol. 2010 Oct;17:2787-94.

[76] Yang X, Stein EW, Ashkenazi S, Wang L V. Nanoparticles for photoacoustic imaging. Wiley Interdiscip Rev Nanomedicine Nanobiotechnology. 2009 Jul 1;1:360-8.

[77] Luke GP, Yeager D, Emelianov SY. Biomedical applications of photoacoustic imaging with exogenous contrast agents. Ann Biomed Eng. 2012 Feb 3;40:422-37.

[78] Zhang Y, Yu J, Kahkoska AR, Gu Z. Photoacoustic drug delivery. Vol. 17, Sensors (Switzerland). 
Multidisciplinary Digital Publishing Institute; 2017. p. 1400.

[79] Kim J, Park S, Jung Y, Chang S, Park J, Zhang Y, et al. Programmable Real-time Clinical Photoacoustic and Ultrasound Imaging System. Sci Rep. 2016 Dec 12;6:35137.

[80] Oraevsky AA, Savateeva E V., Solomatin S V., Karabutov AA, Andreev VG, Gatalica Z, et al. Optoacoustic imaging of blood for visualization and diagnostics of breast cancer. 2002;81-94.

[81] Manohar S, Vaartjes SE, van Hespen JCG, Klaase JM, van den Engh FM, Steenbergen W, et al. Initial results of in vivo non-invasive cancer imaging in the human breast using near-infrared photoacoustics. Opt Express. 2007;15:12277.

[82] Ermilov SA, Khamapirad T, Conjusteau A, Leonard MH, Lacewell R, Mehta K, et al. Laser optoacoustic imaging system for detection of breast cancer. J Biomed Opt. 2009;14:24007.

[83] Heijblom M, Piras D, Xia W, van Hespen JCG, Klaase JM, van den Engh FM, et al. Visualizing breast cancer using the Twente photoacoustic mammoscope: What do we learn from twelve new patient measurements? Opt Express. 2012;20:11582.

[84] Zhou Y, Xing W, Maslov KI, Cornelius LA, Wang L V. Handheld photoacoustic microscopy to detect melanoma depth in vivo. Opt Lett. 2014;39:4731.

[85] Chuah SY, Attia ABE, Long V, Ho CJH, Malempati P, Fu CY, et al. Structural and functional 3D mapping of skin tumours with non-invasive multispectral optoacoustic tomography. Ski Res Technol. 2017;23:221-6.

[86] Attia ABE, Chuah SY, Razansky D, Ho CJH, Malempati P, Dinish US, et al. Noninvasive real-time characterization of non-melanoma skin cancers with handheld optoacoustic probes. Photoacoustics. 2017;7:20-6.

[87] Viator JA, Au G, Paltauf G, Jacques SL, Prahl SA, Ren H, et al. Clinical testing of a photoacoustic probe for port wine stain depth determination. Lasers Surg Med. 2002;30:141-8.

[88] van den Berg PJ, Daoudi K, Bernelot Moens HJ, Steenbergen W. Feasibility of photoacoustic/ultrasound imaging of synovitis in finger joints using a point-of-care system. Photoacoustics. 2017;8:8-14.

[89] Favazza CP, Cornelius LA, Wang L V. In vivo functional photoacoustic microscopy of cutaneous microvasculature in human skin. J Biomed Opt. 2011;16:26004.

[90] Taruttis A, Timmermans AC, Wouters PC, Kacprowicz M, van Dam GM, Ntziachristos V. Optoacoustic Imaging of Human Vasculature: Feasibility by Using a Handheld Probe. Radiology. 2016;281:256-63.

[91] Sousa P, Felizardo V, Oliveira D, Couto R, Garcia NM. A review of thermal methods and technologies for diabetic foot assessment. Expert Rev Med Devices. 2015;12:439-48.

[92] Hernandez-Contreras D, Peregrina-Barreto H, Rangel-Magdaleno J, Gonzalez-Bernal J. Narrative review: Diabetic foot and infrared thermography. Infrared Phys Technol. 2016;78:105-17. 


\section{Appendix I}

Database

Scopus (www.scopus.com)

Laser Doppler Perfusion Imaging (Title. Abstract and Keywords)

TITLE-ABS-KEY ( ( laser AND doppler ) AND ( diabetic AND foot ) AND ( circulation OR microcirculation ) ) AND ( LIMIT-TO ( DOCTYPE, "ar " ) OR LIMIT-TO ( DOCTYPE, " re " ) ) AND ( LIMIT-TO ( LANGUAGE , "English " ) )

Laser Speckle Contrast Imaging (Full text)

ALL ( ( laser AND speckle ) AND ( diabetic AND foot ) AND ( circulation OR microcirculation ) ) AND ( LIMITTO ( DOCTYPE, "ar " ) OR LIMIT-TO ( DOCTYPE, " re " ) ) AND ( LIMIT-TO ( LANGUAGE , "English " ) )

Hyperspectral Imaging (Full text)

ALL ( ( hyperspectral ) AND ( diabetic AND foot ) AND ( circulation OR microcirculation) ) AND ( LIMIT-TO ( DOCTYPE , "ar " ) OR LIMIT-TO ( DOCTYPE, " re " ) ) AND ( LIMIT-TO ( LANGUAGE, "English " ) )

Photoacoustic Imaging (Full text)

ALL ( ( photoacoustic OR optoacoustic ) AND ( diabetic AND foot ) AND ( vascularization ) ) AND ( LIMITTO ( DOCTYPE, "ar " ) OR LIMIT-TO ( DOCTYPE, " re " ) ) AND ( LIMIT-TO ( LANGUAGE, "English " ) ) 